\title{
The initial impact of low-level laser therapy on a traumatic leg ulcer
}

\section{Jose Maria Pereira de Godoy1, Lívia Maria Pereira de Godoy², Esteban Fortuny Pacheco ${ }^{3}$, Maria de Fátima Guerreiro Godoy ${ }^{4}$}

${ }^{1}$ Cardiology and Cardiovascular Surgery Department of the Medicine School in São José do Rio Preto (FAMERP), $\mathrm{CNPq}$ (National Council for Research and Development), Brazil, ${ }^{2}$ Physician specialized in General Practice, Resident in Dermatology Service in Instituto Lauro de Souza Lima-ILSL-Bauru and Researcher Group of the Clínica Godoy, São José do Rio Preto, SP, Brazil, ${ }^{3}$ Physiotherapist, Teacher in University Finis Terrae, Chile, ${ }^{4}$ Occupational Therapist professor of the Post-Graduate Stricto Sensu in Medicine School in São José do Rio Preto (FAMERP) and Research Group in the Clínica Godoy, Sao Jose do Rio Preto, Brazil

Corresponding author: Jose Maria Pereira de Godoy, MD PhD, E-mail: godoyjmp@gmail.com

\begin{abstract}
Low-level laser therapy (LLLT) has been used as an effective, safe, and noninvasive treatment for wound healing. This paper reports the case of a 78-year-old female who had suffered trauma to the anterior tibial region of the leg. The injury continued to worsen for a month, along with an increase in pain, even with medical treatment involving antibiotics and conventional bandaging. An examination revealed a hyperemic injury with secretions, and LLLT was proposed, with red laser at $3 \mathrm{~J}$ and $660 \mathrm{~mW}$ and for a $25 \mathrm{~s}$ exposure time. The patient returned after four days reporting a substantial improvement in both the pain and the wound. Low-level laser therapy (LLLT) proved effective at controlling pain and improving the healing of a traumatic ulcer that had been worsening with conventional treatment.
\end{abstract}

Key words: Low-level laser therapy; Traumatic leg ulcer; Treatment

\section{INTRODUCTION}

Low-level laser therapy (LLLT) has been used as an effective, safe, and noninvasive treatment for wound healing. This therapeutic modality accelerates the healing process by stimulating microcirculation, the proliferation of fibroblasts, the formation of granulation tissue, the synthesis of collagen, and the modulation of the immune system [1,2].

According to a review study, a variety of light sources, such as LEDs and lasers, have been used, each with specific advantages and limitations. However, there is no consensus on treatment parameters, such as wavelength and dose, and different results are reported in the studies reviewed [3]. One study reports a significant reduction in pain in ulcers treated with LLLT [4]. Another study, on the other hand, states that this treatment modality is not an efficient method for the treatment of venous ulcers on the legs [5].

LLLT is considered an effective complementary treatment, especially for inflammation and wounds from skin injuries [6]. Positive effects include acceleration of the tissue repair process, an increase in the formation of granulation tissue, contraction of the wound, modulation of the inflammation, and a reduction in pain [7]. The aim of this study was to report the change in the evolution of a traumatic leg ulcer with the administration of low-level laser therapy.

\section{CASE REPORT}

This paper reports the case of a 78-year-old female who had suffered trauma to the anterior tibial region of the leg. The injury continued to worsen for a month, along

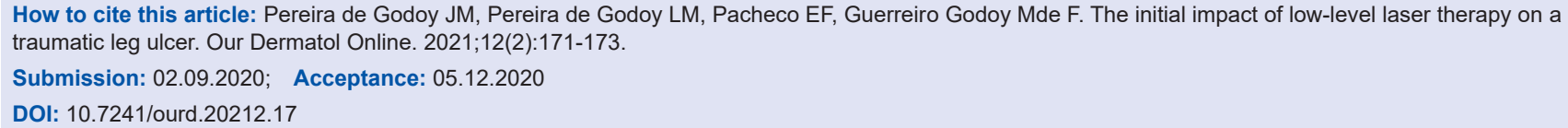


with an increase in pain, even with medical treatment involving antibiotics and conventional bandaging. The patient consulted us on February 27. An examination revealed a hyperemic injury with secretions (Fig. 1), and LLLT (Eco Reability / Ecco Fibras) was proposed, with red laser at $3 \mathrm{~J}$ and $660 \mathrm{~mW}$ and a 25 s exposure time (Table 1). Besides the laser, conventional bandaging was maintained. The patient returned after four days, on March 3, reporting a substantial improvement in both the pain and the wound (Fig. 2). A substantial improvement was noted in the hyperemia, along with a reduction in the size of the ulcer and the formation of a fibrin film on the wound. Another session of LLLT was performed and the patient was instructed to leave the wound uncovered, allowing the fibrin film to serve as a biological bandage. After seven days, on March 9, the patient returned without pain and with a substantial improvement in the wound (Fig. 3). The patient returned again on March 16 with the wound healed almost completely (Fig. 4). This study was approved by

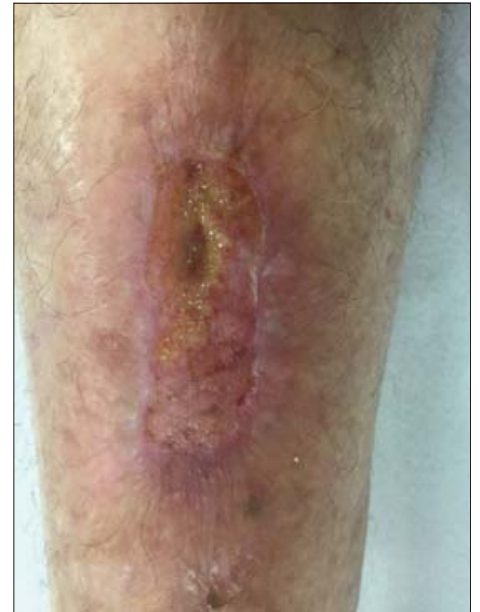

Figure 1: The first examination revealed a hyperemic injury with secretions.

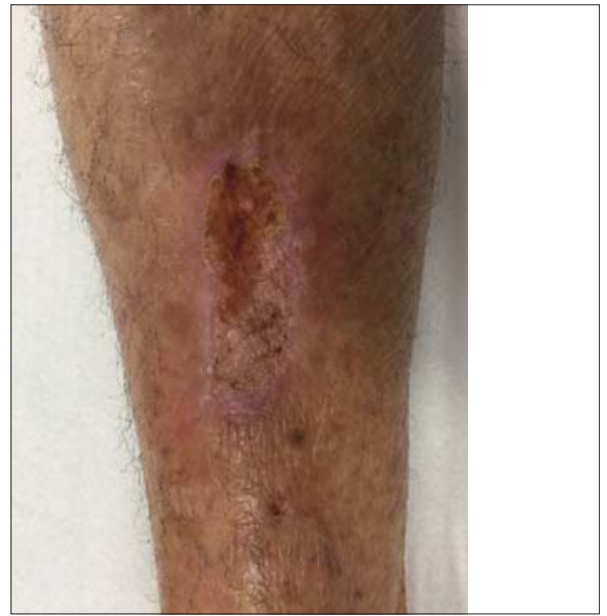

Figure 2: A substantial improvement in both the pain and the wound. the Ethics and Research Committee of Faculdade de Medicina de São José do Rio Preto (FAMERP), Brazil (\#4.027.569).

\section{DISCUSSION}

This study observed a remarkable change in the evolution of a traumatic ulcer in the tibial region. There is no consensus, in the literature, on the laser treatment for ulcers, and a wide range of parameters are reported, which may compromise the results. Some effects of LLLT are well-reported, such as improvement in pain, as in our case. The patient was taking an analgesic three times a day, but only needed to take it once in the four days after the first laser therapy session. The mechanism of the reduction in pain that was proposed is a hormonal or opioid response dependent on the wavelength and dose.

We standardized the wavelength parameter to enable better evaluation of the results and to identify the

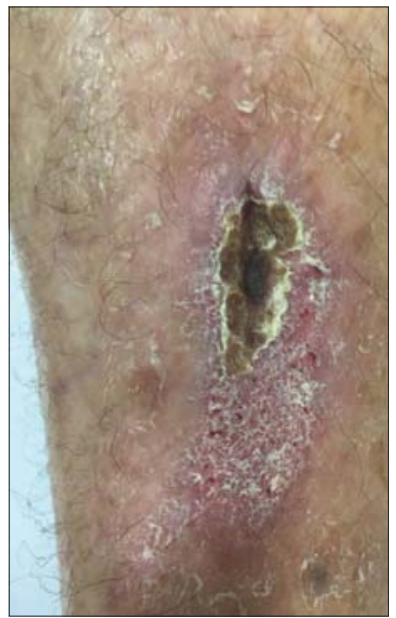

Figure 3: A substantial improvement of the wound.

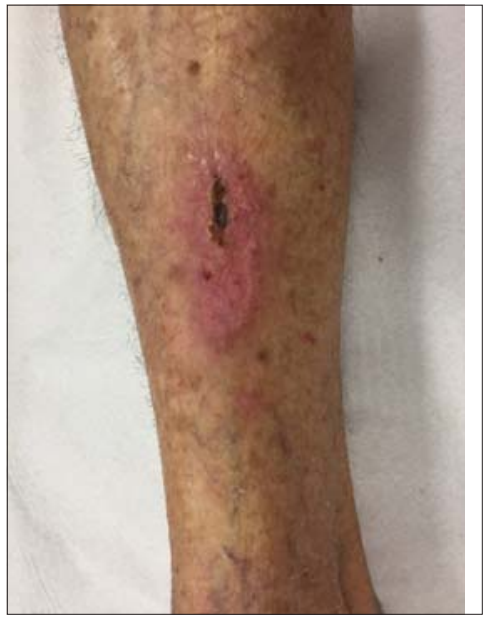

Figure 4: The wound healed almost completely. 
Table 1: Laser parameters.

\begin{tabular}{lc}
\hline Apparatus & Eco Reability (Ecco Fibras) \\
\hline Wavelength & $660 \mathrm{~nm}$ \\
Form of application & Punctual \\
Power & $3 \times 100 \mathrm{~mW}$ \\
Energy & $3 \mathrm{~J} \mathrm{by} \mathrm{point}$ \\
Total energy on the emitter surface & $9 \mathrm{~J}(3 \mathrm{emitters}, 3 \mathrm{~J}$ each $)$ \\
Emitter surface & $9 \mathrm{~cm}^{2}(1,5 \times 3 \mathrm{~cm})$ \\
\hline
\end{tabular}

best option for each ulcerated injury. Another striking aspect of this case was the change in the evolution of the wound, which had been worsening steadily prior to LLLT and improved abruptly with this therapeutic modality (Figs. 1 -4). The only change to the original treatment was the addition of LLLT. On the patient's first return to the clinic, she reported a reduction in pain and there was a substantial improvement in the wound, along with the formation of a fibrin film on the entire ulcer. Thus, the decision was made not to continue bandaging.

The improvement in hyperemia suggests that LLLT modulated the inflammatory process. The injury had no venous components and was located in the proximity of the tibia, which explains the difficulty in healing with conventional bandaging. These findings suggest that LLLT may be a complementary therapy for such patients.

The literature offers conflicting results regarding the efficacy of LLLT. Moreover, there is a fundamental need to standardize the parameters of LLLT. This was one of our objectives, and more studies are being undertaken to improve our understanding of laser therapy.

\section{CONCLUSION}

Low-level laser therapy proved effective at controlling pain and improving the healing of a traumatic ulcer that had been worsening with conventional treatment.

\section{Consent}

The examination of the patient was conducted according to the principles of the Declaration of Helsinki.

The authors certify that they have obtained all appropriate patient consent forms, in which the patients gave their consent for images and other clinical information to be included in the journal. The patients understand that their names and initials will not be published and due effort will be made to conceal their identity, but that anonymity cannot be guaranteed.

\section{REFERENCES}

1. Nilforoushzadeh MA, Kazemikhoo N, Mokmeli S, Zare S, Dahmardehei M, Vaghar Doost R, et al. An open-label study of lowlevel laser therapy followed by autologous fibroblast transplantation for healing grade 3 burn wounds in diabetic patients. J Lasers Med Sci. 2019;10(Suppl 1):S7-S12.

2. Bihari I, Mester AR. The biostimulative effect of low-level laser therapy of long-standing crural ulcers using helium-neon laser, helium-neon plus infrared lasers, and noncoherent light: preliminary report of a randomized double-blind comparative study. Laser Ther. 1989;1:97-8.

3. Mosca RC, Ong AA, Albasha O, Bass K, Arany P. Photobiomodulation therapy for wound care: a potent, noninvasive, photoceutical approach. Adv Skin Wound Care. 2019;32:157-67.

4. Vitse J, Bekara F, Byun S, Herlin C, Teot L. A double-blind, placebo-controlled randomized evaluation of the effect of lowlevel laser therapy on venous leg ulcers. Int J Low Extrem Wounds. 2017;16:29-35.

5. Taradaj J, Franek A, Blaszczak E, Polak A, Chmielewska D, Krol P, et al. Using physical modalities in the treatment of venous leg ulcers: A 14-year comparative clinical study. Wounds. 2012;24:215-26.

6. Wang L, Hu L, Grygorczyk R, Shen X, Schwarz W. Modulation of extracellular ATP content of mast cells and DRG neurons by irradiation: Studies on underlying mechanism of low-level-laser therapy. Mediators Inflamm. 2015;2015:630361.

7. Xu L, Zhang C, Xu N, Liu S, Zhou L. Quantum theory analysis on microscopic mechanism of low-level laser irradiation mending rheology for blood. Optoelectron Lett. 2010;6:77-80.

Copyright by Jose Maria Pereira de Godoy, et al. This is an open access article distributed under the terms of the Creative Commons Attribution License, which permits unrestricted use, distribution, and reproduction in any medium, provided the original author and source are credited.

Source of Support: Nil, Conflict of Interest: None declared. 